\title{
Applying Design and Technology Education in Addressing Farmers' Problems in the Makonde Rural District, Zimbabwe
}

\author{
Peter Kwaira and Mishack T. Gumbo \\ ${ }^{1}$ Department of Technical Education, University of Zimbabwe, Box Mp167, \\ Harare, Zimbabwe \\ E-mail: petkwaira@gmail.com \\ ${ }^{2}$ Office of Graduate Studies and Research, College of Education, University of South Africa, \\ P.O. Box 392, University of South Africa \\ E-mail: gumbomt@unisa.ac.za
}

KEYWORDS Design and Technology Education. Developmental Research. Food Processing. Participatory Research. Rural Farmers

\begin{abstract}
This paper reports on the results of a developmental and participatory research study that is coupled with a significant, ongoing and long-term community development project in the Makonde Rural District, Northwestern Zimbabwe. From the beginning, this project has involved the application of Design and Technology Education in problem-solving with the intention to help farmers develop a sustainable localised model of technology for the processing and production of maizemeal, peanut butter and cooking oil. Following design principles adopted from literature, various machines were designed and developed for the purpose. The results and findings reported here include those drawn from the scientific/technical observations made during the development of these machines, followed by the interviews conducted with participants/end users.
\end{abstract}

\section{INTRODUCTION}

This paper reports on a significant, ongoing and long-term community project in the Makonde Rural District, (northwest of Zimbabwe), launched in 2006, after researchers attended several meetings at the invitation of newly resettled farmers. The main subject under discussion at these meetings was community development, where several challenges and problems were highlighted; chief among which featured ageneral lack of resources to support developmental activities. Sentiments expressed by the majority of farmers during these meetings, regarding what theywanted tosee done in an effort to improve their situation were considered to be an important and valid contribution towards the design brief.

From the several problems, these researcherssaw an opportunity to create appropriate and context-relevant solutions to address specific practical problems in the area of food processing. There was a critical need for low-cost, appropriate technology to produce maize meal, peanut butter and cooking oil, leading to the design, making and trial running of experimental grinding mills, oil presses and peanut butter making machines.

Farmers in other parts of Zimbabwe and indeed, other countries have experienced similar problems. For instance, similar cases have been reported in India and Ethiopia, where simple pieces of technology were developed to process and produce various food items at domestic levels (Haidar et al. 2008). In Ethiopia, researchers even went so far as to develop simple household mills to process coffee beans and other crops (Thurnham2008). Through consultation, local communities (end users) were involved in the design and development of solutions to their own problems in keeping with Trebell's (2011) assertion that 'design' is a social activity.More recently, Stables (2014) maintained the same argument focusing on how ordinary people contribute towards the design and development of various products through their roles as consumers/users, guided by their sense of taste.This is where investigations into possible solutions result in literature searches, either through the conventional library or through the internet

In this study, the people of Makonde were considered to be experts in identifying and explaining their problems, before proposing possible solutions. Where one needed to experiment with possible solutions to specific problems, the same people were logically also expected to participate in the testing and evaluation of those solutions in order to check on relevance, appropriateness, effectiveness and efficiency. Stables (2014) considers this to be a necessary step in 
any democratic design process, where the relationship between design and well-being is an issue. Today, this relationship is increasingly being explored to good effect through academic research and professional design, emphasizing on effective ways for designers to engage in participatory design to produce products that support the well-being of others and not just that of their own (Stables 2012).

For the purpose of this paper, it is perhaps important to understand the context within which thepresent phase of the project fits into the scheme of the whole community development project, in terms of the theoretical framework underpinning it. It is at this point that one needs to understand the process of problemsolving, contextualized within a far broader process; ‘design and technology'. Effectively, design and technology (D\&T) is about problemsolving, and to qualify this contention, there was need to consult literature at various levels. The idea of having a process emerging within a process creates a complicated situation requiring one to be clear and specific. Even D\&T itself as a process encompasses two separate processes put together to create yet another process, resulting in a complicated scenario, deserving unpacking. Since according to Potter (2011) and Watkins (2014), designing and problem-solving are essential components underpinning activities in D\&T Education, it became necessary to clarify 'design' and 'technology' as separate entities. Among those who have considered these two terms separately are Roberts and Zanker (1994). Proposing an ideal situation where one demonstrates an understanding of each before relating them, they discard the view that technology encompasses design.

According to Milne (2012), design as an activity involves the use of a wide range of experiences, knowledge and skills to solve problems. It is also about identifying and clarifying problems;responding thoughtfully before creating and testing one's solutions. Reinforcing this view, Wong and Siu (2011) maintain the position that design is a creative activity. One may holdknown facts or ideas at a particular point in time, but the way one combines these to solve a given problem requires creative thinking. Given this background, it appears that design is far more than just problem-solving. It involves the whole process of producing a solution, from conception to evaluation, including elements such as cost, appearance, styling, fashion and manufacture.

On the other hand, technology involves the manipulation of knowledge, skills and available resources to solve/address a problem in a particular environmental context, while at the same time accountingfor the impact this might have on the environment itself (Milne 2012). One might be creative enough to develop a solution to a problem, but if one cannot link this thinking to the available resources in the immediate environment the whole thinking process might not yield the desired results. This is where the link between design and technology is implied. We cannot have a complete solution to a practical problem without the two coming together (Watkins 2014). The situation in Makonde, as reported in this paper has been a typical example. To produce maizemeal, peanut butter and cooking oil, one had to engage in a process that combines the two, that is D\&T, as a fused entity. The situation required one to identify the problem, think critically of possible solutions and imagine the ideal solution in place, before building the relevant machinery for specific problems.

Depending on the situation at hand, there are several models representing the D\&T process. For the purpose of the study reported in this paper, several principles were adopted from the engineering design process developed by Hawkes and Abinett (1984). The six stages in the process included: Stage 1 - the situation for design; Stage 2 - the design brief; Stage 3 investigation into possible solutions; Stage 4 the chosen solution; Stage 5 - realisation; and, Stage 6 - evaluation. These were then operationalizedas explained under Research Design. In practice, it should however be noted that whatever the result at Stage 6, there is always a need to work backwards from stage to stage in order to improve on the solution at various levels in the lifetime of a given project. In Makonde, this has been the situation since 2006, and is likely to continue for the foreseeable future. During the development of the engineering design model, lessons were also drawn from the instructional design models developed by Ally (1997), Romiszowski (1981) and Dick and Carey (1996). In all these models, issues relating to evaluation and the cyclic nature of the design process are typically highlighted. This appears in line with the new thinking propounded by Duell et al. (2014), criticizing the idea of religious- 
ly following specific stages in a linear fashion. Given the challenges upon education in the face of rapid change this century, they propose an approach that allows for flexibility and fluidity in problem-solving. This is why even in this study, the six stages adopted from Hawkes and Abinett's (1984) design process were simply there as tentative guidelines.

In terms of goals, this study set out to address one main research question, subsequently reduced to three sub-levels.

\section{Main Research Question}

This study aimed at addressing the following broad question: What appropriate andless costly technology could be designed and developed to provide a viable system (solution) that would enable farmers in the Makonde Rural District of Zimbabwe to process their crops into specific food items?

\section{Sub-questions}

The main research question was then reduced to the following sub-levels: What kind of machinery could be designed and developed to process and produce maize meal; peanut butter, and cooking oil?

\section{RESEARCH METHODS}

\section{Design}

From a D\&T perspective, the approach in this study was developmental research (DR), where the intentionwas to design, develop and evaluate specific pieces of equipment for the processing of crops into specific food items. This type of research is usually initiated for complex and innovative tasks where very few validated principles are available to structure and support the design and development activities (Lijnse 2000). Typical activities in DR include literature review, participatory research and case studies of current practices (Lijnse 2000).

The design and development of the required machinery as described in thispaper was a cyclic process involving several cycles, with tests and trials in-between, in order to make the necessary adjustments where appropriate and to redesign the machinery where required. The six stages of the design process, outlined under 'Introduction' wereoperationalised as follows:
Stage 1: The Situation for Design (problem situation) - Lack of equipment to process and produce maizemeal, peanut butter and cooking oil was identified as a critical problem inMakonde. Preliminary investigations showed a situationwhere the existing exogenous technology could not really meet the needs of the community. Worse still, in the event of a breakdown, it was also difficult and costly to import spares from afar.

Further analysis of the situation revealed the possibility of addressing the whole problem more effectively using locally available materials. Since the times were hard, the idea was to experiment with scrap materials and recycled electrical components, aiming at coming up with what could be the most appropriate technology in the given situation. There was also need to ensure full participation by the community at every stage, in line with Schumacher's (1973, in Pearce 2012) philosophy emphasizing the importance of technology being locally controlled and people-centered.

Stage 2: The Design Brief (analysis and synthesis of initial ideas) -The task was to design, manufacture and evaluate less costly and relevant machinery from locally available materials to enable farmers to process their produce into maizemeal, peanut butter and cooking oil. This led to the generation of tested solutions (appropriate technology in the form of relevant machinery).

Stage 3: Investigation into Possible Solutions (identifying best aspects of each solution)At this point, possible solutions to the problem were generated for each of the envisaged machines. This entailed intensive consultations and discussionswith farmers, where ideas were shared resulting in possible solutions in the form of sketches. These initial ideas were further examined and weighed to check on the advantages and disadvantages of each,in the process of working towards an ideal solution.

Stage 4: The Chosen Solution (design incorporating the best aspects of each solution from Stage 3)- The chosen solutionfor each case was further developed in preparation for manufacturing. This involved focused attention on specific issues, checking on details mainly relating to; availability of materials, methods of manufacture, capacity (facilities and equipment) and expertise in terms of technical skills. All these details were in view of the establishedareas of 
need regarding the processing/production of maizemeal, peanut butter and cooking oil.

Stage 5: Realization (making)- After identifying the chosen solution in each case, the next step wasto produce the relevant prototype.

Stage 6: Evaluation (testing/trial running the solutions)-The experimental prototypes were taken out into the field for tests and trials with the assistance and full participation of the community. The weaknesses revealed at this stage necessitated a revisit and review of all designs with a view to institute appropriate improvements.

\section{Participants}

Out of several farms in the Makonde Rural District, Long Valley Farm was the starting point. Since this study was community-based with the intention to solve specific practical problems, participants came in through opportunistic inclusion. Those who came for specific help and consultations automatically became part of the study. For example, during the early days of the project between 3 September 2005 andthe end of February 2006, out of the 9 meetings held, an average of 49 farmers out of a possible 55 attended. These were automatically considered a representative sample for investigations during that period and their ideas/views were taken on board in line with stages 1 to 4 of the adopted design process. Investigations werefocused on issues to do with; the problem situation, design brief, identification of possible solutions and selection ofa viable solution in each case, taking from the research questions.

\section{Instrumentation and Data Collection Procedures}

Data were collected at various levels through tests and trials of various materials and mechanisms during machine building, observation of specific activities and interviews with specific individuals of interest. Data collection procedures were mainly guided by the principles of DRin line with the adopteddesign process.For example, the idea of revisiting solutions for the sake of improvement after trial-runningwas a continuous process underpinning the procedures. Instrumentation and data collection respectively went according to the activities associated with the design and development of technology for the production of maize meal, peanut butter and cooking oil.

When the first grinding mill prototype (the cyclone) for maize meal production was found characterised by so many design and engineering problems, it became necessary to go back stage by stage in order to improve it. Although particular attention was paid to stages $6,5,4$ and 3 , going backwards, the rest of the stages were also involved indirectly. Specifically, after the tests/trials at stage 6 revealed excessive vibration and noise, culminating in component failuredue to metal fatigue, a revisit of Stage 5 was necessary in order to check on aspects relating to realization. This subsequently led to stages 4 and 3, where the intention was to reconsider the chosen solution in relation to the initial investigations on possible solutions. One could not avoid stages 2 and 1 since there was a need to revisit the design brief and the original problem situation before redesigning the prototype.

Regarding peanut butter production, the improvement from the $1 / 2$-horsepower domestic prototype to the 10-horsepower industrial machine was necessitated by the need to build on speed and efficiency. While the former took between 1 and $1 \frac{1}{2}$ hours to produce 5 litres of peanut butter, the latter took less than 20 minutes. This was after an evaluation at stage 6 and then working backwards through stages 5, 4, 3, 2 and 1. Initially there did not seem to be anything wrong with the domestic model. The machine had been running from the end of August in 2006 and theusers;mainly women, appeared happy and satisfied. However, after listening to their comments carefully sometime in September 2010, there was need to revisit the design, resulting in ten open-ended interview questions aimed at capturing specific concerns. For a viable strategy, close and systematic observations of users were made with the aid of a five-point checklist designed to establish the number and profile of users queuing for service at any one time (for example elderly women, elderly men, girls and boys). Quantities of stock processed and how often individuals came for service were also issues of interest. There were between 10 and 15 people queuing for service at any one time and often, the majority were elderly women (about 7 in every 10). On average these women produced more than 5 litres of peanut butter every time they came. Given this background, these wom- 
en were the best candidates for interviews and 26 of them out of a possible 47 were selected. Of these women, considering their level of enthusiasm, 4 have since been selected to assist as machine operators after attending a basic short in-house course in safety and general maintenance.

On cooking oil production, it was interesting to note that whilethe people were excited about the idea of pressing their own oil, the machine was still far from being perfect. The people did not seem to see anything wrong with the machine although better results were still possible with more efficiency and better performance. During the early stages of development, samples of oil and cake were obtained from a wellestablished company in Harare. These samples were very useful for the purpose of comparison, regarding the quality of both products. For example, the tests showed that while the quality of the oil was generally acceptable, that of the cake left a lot to be desired, thereby compelling researchersto work backwards stage by stage, trying to locate the actual point(s) at which things could have gone wrong. This meant revisiting the processes of making, choosing the proposed solution, investigating possible solutions, analysing initial ideas and studying the problem as presented by the situation.

\section{RESULTS}

Going by the research questions, results and findings are in this paper presented respectively, in relation to the relevant technology for producing; maize meal, peanut butter and cooking oil.

\section{Maize Meal Production}

This was the first priority area, given the desperation expressed by the people for maizemeal, being a staple food. Several possible solutions were tried ranging from the cyclone to the direct or gravity mill models and prototypes. From simple brainstorming ideas on paper, this long process involved continuously flipping between stages 1 to 4 of the design process. The earliest model on trial worked on the principle of the cyclone and was powered by a 2-pole 10-horsepower 3-phase electric motor fitted with a 300mm-diameter 3-way driver pulley. The milling unit had a 3-way 100mm-diameter driven pul- ley, resulting in a speed ratio of 1:3. With the motor having a basic speed of 1400 revolutions per minute $(\mathrm{r} / \mathrm{m})$, the ultimate speed was $4200 \mathrm{r} /$ $\mathrm{m}$. Being so fast, this machine took less than 2 minutes to process a 20-litre bucket of maize. The community was very happy with thespeed and quality of the meal. For example, the most common comment was:

Hey, chigayo ichi chinozokurumidza, uye upfu hwacho hwakazotsetseka! (English: Hey, this machine is so fast, and the meal is so refined!)

This comment was in response to an openended interview question where several clientsopined their views regarding performance of the machine and quality of the meal.In fact the question was two-fold: "Masevenzero echigayo ichi munoaonao sei, uye upfu hwachinoburitsa munofungei nahwo?" (English: "How do you find the performance of this machine and what do you think about the quality of the meal?”). Despite the positives, the machine was beset with many problems from the beginning. For example, the extremely high speed culminated in so much vibration and excessive noise. Within a month of trial, the machine had developed so many cracks all over the frame and casings. It needed a complete overhaul; welding, rubberising, a change of bearings and overall lubrication. At this point, a new design had to be tried. It was time to start experimenting with the gravity mill, which by then had already been fully developed on paper. Young men and women from the community came up with very useful suggestions, and on several occasions some even volunteered to assist in repairing the machine. This was community participation at its best! This whole process was in line with stages 3 to 6 of the design process. The main component, taken from the cyclone mill was the milling compartment or unit, which was then raised to a higher platform by adding an angle iron frame built onto the existing base. The feeding tray was also adjusted to a smaller size in order to improve on balance. Instead of repairing the existing 2-pole 10-horsepower motor, it was cheaper to buy a second-hand 4-pole 10-horsepower motor retaining the same pulley system,thereby maintaining the speed ratio of $1: 3$. Since the speed of the motor was $1000 \mathrm{r} / \mathrm{m}$ the milling speed was effectively reduced from $4200 \mathrm{r} / \mathrm{m}$ to $3000 \mathrm{r} / \mathrm{m}$. Although the noise level was also reduced there was still a need to reduce it even further by rub- 
berising the milling head and supporting it with appropriately shaped wooden blocks on either side. One major advantage of a gravity mill is its portability. It does not require the special mounting slab usually found on the cyclone. From September 2006, this machine had only one major service involving a change of bearings and sieve besides the more regular greasing every two weeks. So far, this machine has really made a difference in terms of reliability. People are happy with its performance. It takes approximately 5 minutes to process a 20-litre bucket of maize and the quality of the mealis reasonably good, either straight run or refined. Figure 1 showsthe gravity mill.

\section{Peanut Butter Production}

The first machine here was a low-cost prototype peanut butter-making machine from recycled scrap materials. An old leaking pot was modified to have peanut butter flowing from where it was leaking. The single phase $1 / 2$-horsepower electric motor was taken from a small disused compressor. From this small domestic machine enough funds were raised to enable the design and development of a bigger industrial machine with a 10-horsepower 3-phase electric motor (see Fig. 2). This was a marked improvement in terms of efficiency. While the former took between 1 and 11/2 hours to produce 5 litres of peanut butter, the latter took less than 20 minutes.

Initially, there did not seem to be anything wrong with the domestic model. However, as indicated under Research Methods, after listening carefully to the users' comments, there need to revisit the design. Details regarding specific concerns emerged during interviews with the 26 women selected under Data Collection. Their main concern was speed, and they wanted the machine working faster. For example, in response to the following open-ended question: "Munofungei nemasevenzero echigayo ichi?" (English: "What do you think about the performance of this machine?”), Typical responses included:

"Chigayo chedu chinotibatsira chose asi dambudziko guru nderokunonoka. Dzimwenguva munhu anotokotsira aka mirirakugaya!” (English: Our machine is very useful and helpful. However, the main problem is that it is too slow and sometimes one goes to sleep while waiting for service!);

and

"Hongu chigayo ichi chinosevenza zva kanaka chose pakutsetsa, asi tinoda kuti chive chinokurumidza kuitirakuti tigowananguvay

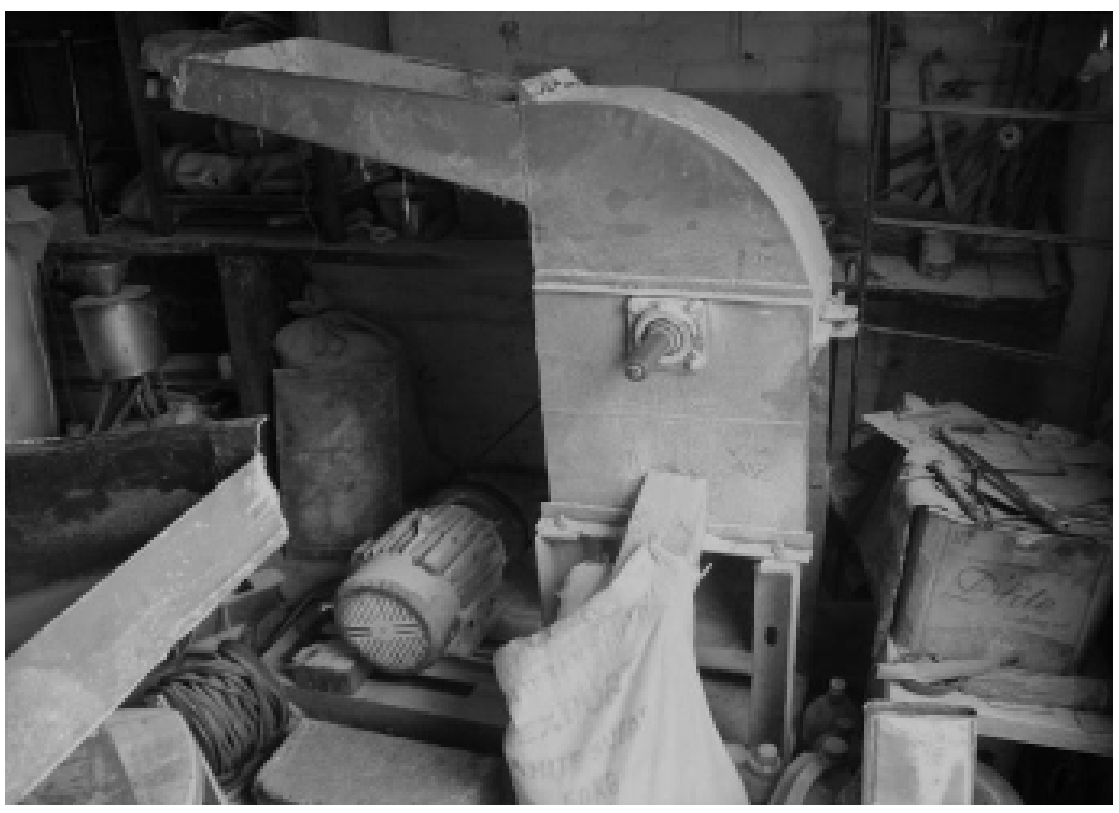

Fig. 1. Thegravity mill Peanut Butter Production 
yokundoita mamwe mabasa kumba”. (English: Yes, the machine works very well in terms of quality of the peanut butter, but we want it faster so that we can have the time to go and do other activities at home.)

This is how the industrial model in Figure 2 became a viable solution in this case.
The equipment developed so far has been especially designed for the processing of sunflower seeds and other seeds that can be pressed cold. Initial trials/experiments showed that cold pressing of soya beans does not result in oil but in a powder; there by necessitating the development of different equipment,

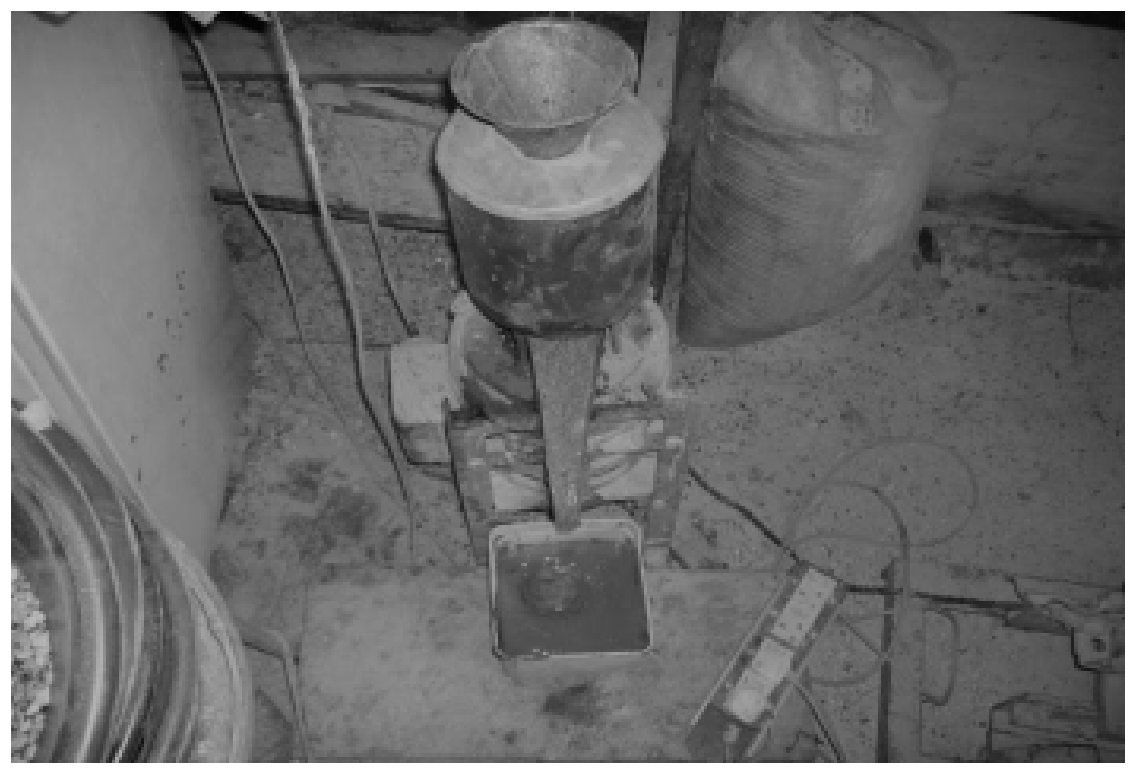

Fig.2.The industrial peanut butter-making machine Cooking Oil production

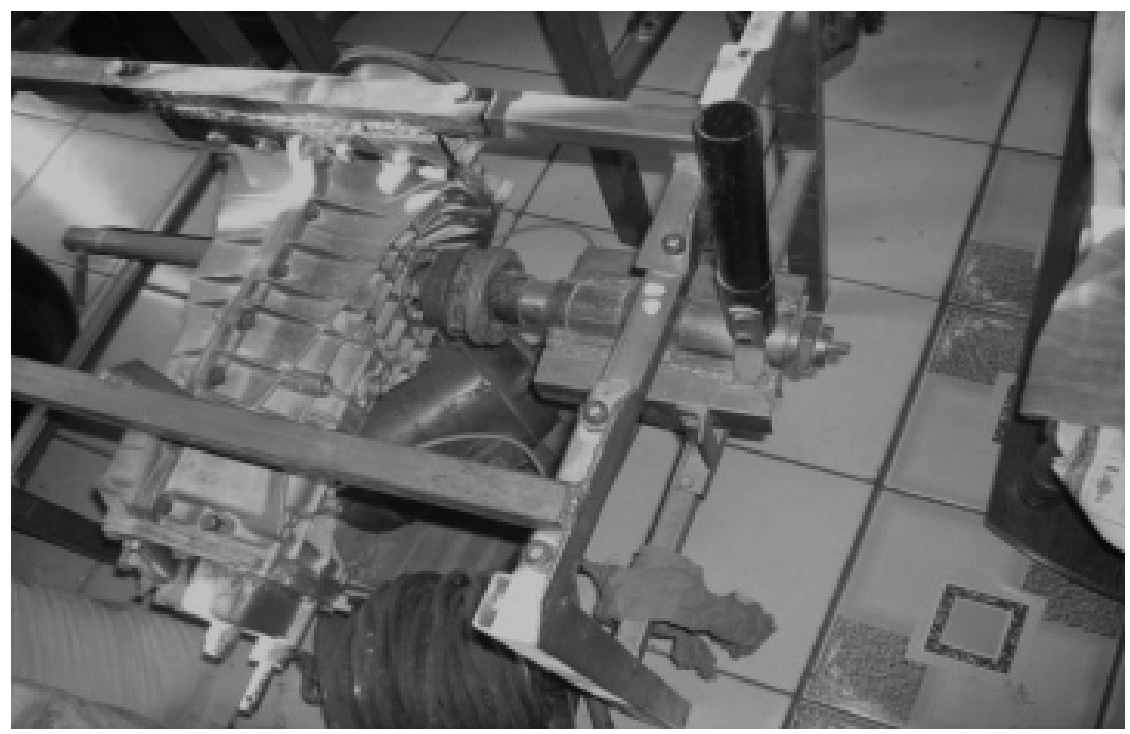

Fig. 3. The oil press 
beyond the scope of this study. With sunflower seed, the results were smooth from the beginning although the equipment still needs attention in terms of efficiency. For example, the cake still remains excessively oily after crushing, squeezing and pressing. The machine in Figure 3 was generated mainly from scrap metals and a second-hand Renault 12 gearbox. It is driven by a 3-horsepower motor converted from 3-phase to single-phase. The good thing about this machine is that it is run on a variable speed mechanism taking from the 4-speed gearbox. In this case, the harder the seed, the heavier the gear, where the first gear is the heaviest. On the other side, there is room for the reverse gear to drive a separate shaft and screw in a separate mechanism for the hardest seed. In fact, there is still a lot of work to be done to improve various aspects of this machinein order to get the most out of it.

Typical examples of products produced from the three categories of machinerydescribed in this paper are depicted in Figure 4.

\section{DISCUSSION}

The results and findings presented in this paper would not have meant much without a discussion of the whole problem-solving process, underpinning all the activities conducted during the study, in keeping with the philosophy of D\&T Education in community development.

As already noted under Research Design ,Schumacher (1973, in Pearce 2012) has been one of the most outstanding proponents advocating for community centred technological development. Taking from Schumacher (1973), Pearce (2012) summarizes the main advice to anybody trying to engage in community development to find out what the people are doing so that they can be helped to do it better. For the farmers in the Makonde Rural District of Zimbabwe, this approach seems to have worked as demonstrated by the experience described in this paper. Farmers were already doing well regarding production in terms of harvests from their fields and that became the foundation for further development, where they needed assistance in order to do better by adding value to their produce. This is how the production of maize meal, peanut butter and cooking oil came about. Starting from what farmers were already doing, it was much easier to help them do it even better. Their active participation at all levels appears to have been motivated by the need to improve their situation thereby confirming findings by Haider et al. (2008) and Thurnham (2008) in India and Ethiopia, where they respectively found local communities actively involved in seeking solutions to their problems under similar circumstances.

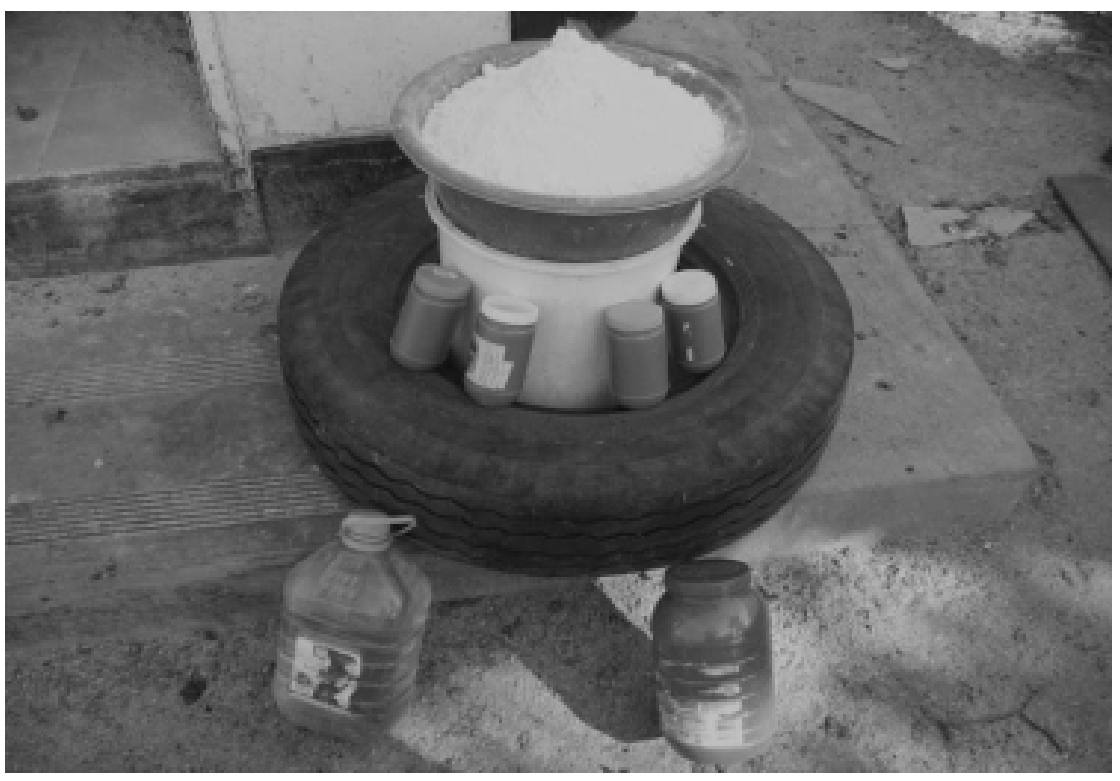

Fig. 4. Maize meal, peanut butter and cooking oil after processing 
As already indicated under 'INTRODUCTION', such community participation in problem-solving has in this paper been found in keeping with Trebell's (2011) assertion of D\&T being a social activity. More recently, several educationists have unanimously agreed in their support of the same contention, with Duell et al. (2014), Goatman and Moody (2014), Gray and Siegel (2014), Stables (2014), Taboada and Coombs (2014), and Watkins (2014) being the most outstanding.

The idea of consulting and actively involving members of the community in the design and development of solutions to their problems as indicated in this paper helped to instill a sense of ownership in them. Once community members own a solution to their problems, they are also likely to develop a sense of responsibility, which is a crucial step towards 'designerly wellbeing'; a phenomenon with several implications on the teaching and learning of D\&T (Stables 2014; Butcher and Schaber 2012). Given the power of today's technological processes, society and individuals really need to be empowered in order to make informed decisions on what, how, and when to develop or use various technological systems. Since technological issues are usually relative, depending on the nature of society, it helps to have decision making processesreflecting the values and beliefs of individual societies in order to help them reach their goals. This implies all citizens acquiring a base level of technological literacy; enabling them to use, manage, and understand technology (Stables 2012). However, although this sounds attractivewhere these aspects are anatural progression, focusing on learning how toproduce solutions/ design outcomes poses a major challenge for student engagement in courses that focus on the more theoretical and philosophical, mediaindependent views of D\&T (Taboada and Coombs 2014).

Coming to what transpired in the study reported in this paper, the findings were interesting in one major respect; although none of the participants had received any formal education/ training in D\&T, the level of enthusiasm driving their participation was phenomenal. Initially, it was difficult to understand or explain this phenomenon until after coming across Princen's (2010) findings in Stables (2014). In his work as an ecologist, Princen (2010) discovered that humans are naturally at their best when they are faced with a genuine challenge, creative and pro- ductive, able to find meaning in their own problem-solving, able to see the possibility of helping themselves as well as others, and able to organize or govern themselves. These capabilities clearly show that all human beings are naturally designers and their ability to think creatively and critically is one of the defining characteristics of being human (Stables 2014; Princen 2010; Baynes 2006). Eventually, this reinforced the understandingthat, apart from D\&T being a social issue as maintained by Trebell (2011), it is above all, a matter of survival.

\section{CONCLUSION}

Farmers and villagers at Long Valley Farm in the Makonde Rural District of Zimbabwe are now able to produce maizemeal, peanut butter and cooking oil, not only for subsistence purposes, but alsofor sell to generate income. Apart from the oil press which still needs attention in terms of efficiency, all the other machines are now working perfectly. The good thing about this project is that since inception in 2006, it has remained self-funded, surviving through support from the community. Members have been offering to pay for serviceseither in cash or through barter trade. The latter system has involved members contributinga portion of the produce to be processed. This continued support has allowed for further research at various stages of the project.

It is interesting to note that while the project has been based at Long Valley Farm, it has also been a sanctuary for community development attracting so many people from neighbouring farms, some of whom have travelled from as far as 25 kilometers. This has been an indication of the need to open more community-based research stations and projects around the district, with a potential to expand into more districts and provinces throughout the country. Given the outcome of this study, the researchers are enthused and poised to take on this challenge. The constructivist problem-solving principles applied in this study helped to instill commitment in the people, who besides identifying their own problems, also partook in the creation of solutions to those problems.

Implications of these conclusionson the long term plans of the project have been realised in relation to three broad issues: the future, D\&T Education, and a shared model of problem-solv- 
ing at community level between Zimbabwe and South Africa.

From Long Valley Farm in Makonde, the longterm intention is to spread the idea and involve more communities in the district and beyond. By involving women and youths, the ultimate goal is also to contribute toward employment creation in order for the community to be self-reliant and selfsustained thereby reducing poverty.

Essentially, this paper has shown D\&T being fundamentally about problem-solving, requiring educationists to lead by example as they engage students in meaningful activities, where they deal with real-life problems through actionbased developmental research.

Still looking into the future, chances are high that there could be a similar situation in South Africa,where rural communities could benefit from the Zimbabwean experience. While the problems might not necessarily be exactly the same, the idea remains basically the same, that is the need to share/exchange ideas regarding community involvement in problem-solving. There is potentially a likelihood of this idea spreading to other SADC countries through further collaborative research efforts.

\section{RECOMMENDATIONS FOR FURTHER RESEARCH}

Having seen the importance of community participation in problem-solving as was the case in the study reported in this paper, one main challenge could be the need to find out how the principles of D\&T in relation to community development highlighted in this paper could be accommodated and promoted in existing curricula at various levels in schools. This could be another platform where experiences could be shared between South Africa and Zimbabwe through comparative and collaborative research.

It would also be interesting to find out how teacher education/training could be revisited with a view to make the necessary adjustments in order to keep abreast of innovationsin given curricula, depending on the situation and context.

\section{LIMITATIONS OF THE STUDY}

Despite similarities between the problems experienced by farmers/villagers in Makonde and those experienced by similar communities elsewhere in Zimbabwe or outside, the results and findings presented in this paper reflect the situation and experiences of one particular community at Long Valley Farm in Makonde. It is specifically the ideas and views of this particular community that were taken on board during the design and realization of the various pieces of machinery/technology developed during the study reported in this paper. While specific machines performed to specific levels/degrees of satisfaction, it does not necessarily mean that they will have the same impact elsewhere, despite similarities in terms of the nature of problems. Where one would be tempted to borrow ideas from this paper to solve similar problems elsewhere by adapting various solutions for application in a specific context, one would still need to investigate and find out what views and preferences individual communities hold regarding the relevance and appropriateness of specific solutions to specific problems in their contexts.

\section{REFERENCES}

Ally M 1997. Instructional Design. Alberta: Grant MacEwan Community College.

Baynes K 2006. Design education: what's the point? Design and Technology Education: International Journal,11(3): 7-10.

Butcher J, Schaber F 2012. Undergraduate Design Learning in Multiple Partnerships: Joined Up Design for Academies. International Journal of Design and Technology Education. From <www.citeulike.org/article/ 10381353> (Retrieved on 21 May 2012).

Dick W, Carey L 1996. Instructional Design Models. Belmont: Brook and Cole.

Duell C, Wright N, Roxburgh J 2014. Developing 'design minds' for the 21 st century through a public sector initiated online design education platform. Design and Technology Education: An International Journal, 19(1): 67-74.

Haidar J, Demissie T, Kloos L 2008. Vitamin 'A' deficiency in Ethiopia in the last 50 years. Sight and Life Magazine, Issue 2: 25-31.

Hawkes B, Abinett R 1984. The Engineering Design Process. Singapore: Longman.

Goatman M, Moody L 2014.The changing nature and definitions of industrial design and implications for prospective undergraduate students. Design and Technology Education: An International Journal, 19(1): 21-29.

Gray CM, Siegel MA 2014. Sketching design thinking: Representations of design in education and practice. Design and Technology Education: An International Journal, 19(1): 47-61.

Lijnse P 2000. Didactics of science: The forgotten dimension in science education research? In: R Millar, J Leach, J Osborne (Eds.): Improving Science Education: The Contribution of Research. Buckingham: Open University Press, pp. 308-326.

Milne L 2012. Nurturing The Designerly Thinking and Design Capabilities of Five-Year-Olds: Technology in the New Entrant Classroom. International Journal 
of Design and Technology Education. From <www. springerlink.com/index/y11815382wg2h327. pdf> (Retrieved on 22 May 2012).

Pearce JM 2012. The case for open source appropriate technology. Environment, Development and Sustainability, 14: 425-431.

Potter P 2011. Technologists Talk: Making the Links between Design, Problem-Solving and Experiences with Hard Materials. International Journal of Design and Technology Education. $<$ www.citeulike.org/article/8985115> (Retrieved on 22 May 2012).

Princen, T 2010.Treading Softly: Paths to Ecological Order.Cambridge: MIT Press.

Roberts P, Zanker F 1994. NADE's response to the SCAA national curriculum, summer, 1994: Design and technology. The Journal Association for Design Education,2: 4-5.

Romiszowski AJ 1981. Designing Instructional Systems. New York: Kogan Page.

Stables K 2012. Designerly well-being: Can mainstream schooling offer a curriculum that provides a foundation for developing the lifelong design and technological capability of individuals and societies? Paper presented in PATT 26 Conference: Technology Education in the $21^{\text {st }}$ Century, in KTH Royal Institute of Technology, Stockholm, June 26 to 30, 2012.
Stables K 2014. Designerly well-being: Implications for pedagogy that develops design capability. Design and Technology Education: An International Journal, 19(1): 9-20.

Taboada M, Coombs G 2014. Liminal moments: Designing, thinking and learning. Design and Technology Education: An International Journal, 19(1): 30-39.

Trebell D 2011.Studying the Effectiveness of Conceptual Design in Secondary Design and Technology in England. International Journal of Design and Technology Education. From <www.citeulike.org/article/ 9249898> (Retrieved on 24 May 2012).

Thurnham D 2008.Nutritional status in the Sidama Region of Southern Ethiopia.In: SB Tanda (Ed.): Sight and Life Magazine, Issue 2: 41-48.

Watkins M 2014.Towards an understanding of the social aspects of sustainability in product design: Teaching HE students in the UK and Ireland through reflection and peer learning. Design and Technology Education: An International Journal, 19(1): 40-47.

Wong YL, Siu KWM 2011. A Model of Creative Design Process for Fostering Creativity of Students in Design Education. International Journal of Design and Technology Education. From <www.springerlink.com/ index/R817808233150G12.pdf>. (Retrieved on 24 May 2012). 